\title{
Occupational Exposures to Ebola Virus in Ebola Treatment Center, Conakry, Guinea
}

\author{
Hélène Savini, Frédéric Janvier, \\ Ludovic Karkowski, Magali Billhot, Marc Aletti, \\ Julien Bordes, Fassou Koulibaly, \\ Pierre-Yves Cordier, Jean-Marie Cournac, \\ Nancy Maugey, Nicolas Gagnon, Jean Cotte, \\ Audrey Cambon, Christine Mac Nab, \\ Sophie Moroge, Claire Rousseau, \\ Vincent Foissaud, Thierry De Greslan, \\ Hervé Granier, Gilles Cellarier, Eric Valade, \\ Philippe Kraemer, Philippe Alla, Audrey Mérens, \\ Emmanuel Sagui, Thierry Carmoi, \\ Christophe Rapp
}

We report 77 cases of occupational exposures for 57 healthcare workers at the Ebola Treatment Center in Conakry, Guinea, during the Ebola virus disease outbreak in 2014-2015. Despite the high incidence of 3.5 occupational exposures/ healthcare worker/year, only $18 \%$ of workers were at high risk for transmission, and no infections occurred.

$\mathrm{O}$ ccupational infections during the West Africa Ebola virus disease (EVD) outbreak in 2014-2015 were a major concern because this outbreak caused 109 deaths among the healthcare workers in Guinea (1). There was also international concern when secondary cases occurred in Spain and the United States (2,3).

The Healthcare Workers Treatment Center in Conakry, Guinea, sought to diagnose and treat healthcare

Author affiliations: French Military Teaching Hospital Laveran, Marseille, France (H. Savini, P.-Y. Cordier, S. Moroge,

P. Kraemer, E. Sagui); French Military Teaching Hospital Saint Anne, Toulon, France (F. Janvier, J. Bordes, J. Cotte, G. Cellarier, P. Alla); French Military Teaching Hospital Legouest, Metz, France (L. Karkowski, N. Gagnon); French Military Teaching Hospital Val de Grâce, Paris, France (M. Billhot, A. Cambon, T. De Greslan, T. Carmoi); French Military Teaching Hospital Percy, Clamart, France (M. Aletti, J.-M. Cournac, C. Mac Nab, V. Foissaud); Guinean Military Health Services, Conakry, Guinea (F. Koulibaly); Frégate Européenne Multi-Mission Aquitaine, Bordeaux Consortium for Regenerative Medicine, Brest, France (N. Maugey); French Military Teaching Hospital Clermont Tonnerre, Brest, France (C. Rousseau, H. Granier); Institut de Recherche Biomédicale des Armées, Brétigny sur Orge, France (E. Valade); French Military Teaching Hospital Bégin, Saint Mandé, France (A. Mérens, C. Rapp)

DOI: https://doi.org/10.3201/eid2308.161804 workers with suspected or proven EVD by offering extensive medical care (e.g., blood or plasma transfusions, central venous catheterization, biologic monitoring). This center had 5 persons with suspected EVD and 9 persons with confirmed EVD.

The first objective of this study was to describe the occupational exposures occurring in the Healthcare Workers Treatment Center. The second objective was to analyze factors associated with the frequency of highrisk exposures.

\section{The Study}

A total of 66 volunteers from the French Armed Forces Medical Service worked in the high-risk zone for EVD. These volunteers wore personal protective equipment (PPE): coveralls with hoods, large goggles, waterproof respirator masks that filter $\geq 94 \%$ of airborne particles, waterproof overshoes, a double pair of nitrile gloves, and a third pair of latex gloves. They followed preliminary biosafety training on basic rules, prevention of percutaneous injuries, and management of incidents in exposed or infected areas (e.g., skin exposure, body fluid projection, fainting). Because removal of PPE was considered the highest risk for virus transmission (4), we opted for PPE removal by protected persons trained to undress persons without spraying the high-risk zone with bleach.

We conducted a descriptive prospective study during January 23-May 8, 2015, of all occupational exposures in the high-risk zone and reported by a healthcare worker. Occupational exposure was defined as any malfunction of PPE or any noncompliance of biosafety protocols in the high-risk zone. Incidental and demographic data, risk evaluation, and interventions were obtained by using a standardized questionnaire for all reported exposures.

When an exposure occurred, the exposed healthcare worker had to report the exposure to the physician at the Healthcare Workers Treatment Center. This physician used a detailed questionnaire to obtain information on conditions of exposure and evaluated the risk for transmission as low or high, as per French recommendations (Table 1) (5). On the basis of results of this evaluation, clinical monitoring or postexposure prophylaxis (PEP) with favipiravir was prescribed. Correlates of risk exposure were examined by using the $\chi^{2}$ test for categorical variables and the MannWhitney test for continuous variables.

A total of 22 healthcare workers from Guinea with confirmed EVD were treated in the Healthcare Workers 
Table 1. Risk levels of transmission factors for Ebola virus disease for healthcare workers, Conakry, Guinea*

\begin{tabular}{lcc}
\hline & \multicolumn{2}{c}{ Risk level } \\
Exposure & $\begin{array}{c}\text { EVD with diarrhea, vomiting, } \\
\text { and hemorrhaging }\end{array}$ & $\begin{array}{c}\text { EVomith diarrhea, } \\
\text { vomiting, and hemorrhaging }\end{array}$ \\
\hline Contact $(\geq 1 \mathrm{~m})$ with patients not projecting biological fluids & Low \\
Close contact $(<1 \mathrm{~m})$ with patients not projecting biological fluids & Low & High \\
Direct contact with biological fluids & High & High \\
Cumulative incidents during removal of PPE & Low & High \\
Transcutaneous or mucosal exposure to infected biological fluids & Maximum & Maximum \\
\hline${ }^{*}$ Adapted from recommendations of the French High Council on Public Health (5). EVD, Ebola virus disease; PPE, personal protective equipment.
\end{tabular}

Treatment Center during the study. These workers represented $85 \%$ of infected healthcare workers from Guinea during the same period. Six of these workers died (mortality rate $27 \%$ ). None of them worked in an Ebola Treatment Center but all were infected in their community or in other public/private healthcare facilities when not using PPE. During January 23-May 8, 2015, healthcare workers from France at the Healthcare Workers Treatment Center had 3,081 encounters with the high-risk zone for EVD. A total of 77 cases of occupational exposures in the high-risk zone were reported by 57 healthcare workers (30 nurses) from France, which represented an incidence of 2.5\% (3.5 occupational exposures/worker/y) (Table 2). Most (62, 80.6\%) workers had a low risk for virus transmission.

The most frequent type of exposure incident $(n=63)$ was exposure of healthy skin on the face because goggles or respirator masks did not stay correctly in place during patient care. Only 4 healthcare workers reported problems during removal of PPE. Only 14 high-risk occupational exposures were reported; 11 were exposures of healthy skin $\leq 1 \mathrm{~m}$ from a patient projecting biologic fluid, 2 were projections of biologic fluids to healthy skin, and 1 was fluid projection to mucous membranes. This final incident occurred during discharge of a cured patient who had an undetectable viral load. Percutaneous exposure did not occur during the study period.

Age, sex, carrying glasses, activity, experience with an activity, duration of the activity in the high-risk zone, exposure time, and time of the study were not associated with a higher frequency of high-risk exposure. The only factor associated with high-risk exposure was obtaining a blood sample $(\mathrm{p}=0.016)$. Most $(72.7 \%)$ occupational exposures occurred during the first month of the study. For all exposures, skin disinfection with $0.05 \%$ sodium hypochlorite and monitoring of body temperature were initiated. PEP with favipiravir was not used, and no patients were evacuated to France. EVD did not develop in healthcare workers at the Healthcare Workers

\begin{tabular}{|c|c|c|c|}
\hline Characteristic & Total, $\mathrm{n}=77$ & Low risk, $\mathrm{n}=62$ & High risk, $\mathrm{n}=15$ \\
\hline \multicolumn{4}{|l|}{ Exposure } \\
\hline Healthy skin $\geq 1 \mathrm{~m}$ from patient $\uparrow$ & $52(67.5)$ & $52(83.9)$ & 0 \\
\hline Healthy skin $<1 \mathrm{~m}$ from patient $\dagger$ & $11(14.3)$ & 0 & $11(73.3)$ \\
\hline Mucous membrane $>1 \mathrm{~m}$ from patient & $1(1.3)$ & $1(1.6)$ & 0 \\
\hline Undressing patient & $6(7.8)$ & $6(9.7)$ & 0 \\
\hline Fluid projection on healthy skin $†$ & $2(2.6)$ & 0 & $2(13.3)$ \\
\hline Fluid projection on mucous membrane & $1(1.3)$ & 0 & $1(6.7)$ \\
\hline Percutaneous exposure & 0 & 0 & 0 \\
\hline Other & $4(5.2)$ & $3(4.8)$ & $1(6.7)$ \\
\hline \multicolumn{4}{|l|}{ Exposed worker activity $\ddagger$} \\
\hline Fluid management & $26(33.8)$ & $21(33.9)$ & $5(33.3)$ \\
\hline Patient care or clinical examination & $35(45.5)$ & $28(45.2)$ & $7(46.7)$ \\
\hline Blood samplingt & $13(16.9)$ & $7(11.3)$ & $6(40.0)$ \\
\hline Supervision & $6(7.8)$ & $4(6.5)$ & $2(13.3)$ \\
\hline Undressing patient & $9(11.7)$ & $9(14.5)$ & 0 \\
\hline Other & $5(6.5)$ & $4(6.5)$ & $1(6.7)$ \\
\hline Mean activity duration, $\min$ & 53.5 & 53.9 & 52 \\
\hline \multicolumn{4}{|l|}{ Exposure time interval } \\
\hline 6:00 AM-10:00 AM & $30(39.0)$ & $24(38.7)$ & $6(40.0)$ \\
\hline 10:01 AM-4:00 PM & $16(20.8)$ & $11(17.7)$ & $5(33.3)$ \\
\hline 4:01 PM-8:00 PM & $21(27.3)$ & $18(29.0)$ & $3(20.0)$ \\
\hline 8:01 PM-5:59 AM & $9(11.7)$ & $8(12.9)$ & $1(6.7)$ \\
\hline No data & $1(1.3)$ & $1(1.6)$ & 0 \\
\hline \multicolumn{4}{|l|}{ Time of exposure } \\
\hline First month & $56(72.7)$ & $45(72.6)$ & $11(73.3)$ \\
\hline Last month & $21(27.3)$ & $17(27.4)$ & $4(26.7)$ \\
\hline
\end{tabular}

*Values are no. (\%) unless otherwise indicated.

$\dagger$ Associated with high risk of virus transmission $(p<0.05)$.

$\ddagger>1$ activity was possible. 
Treatment Center during the study or after they returned from Guinea to France.

\section{Conclusions}

To our knowledge, there are few data regarding occupational exposures in a medical facility caring for EVD patients. Limited data are available for potential occupational exposures in an Ebola Treatment Center (6). Rare cases of EVD in healthcare workers have been reported from Africa $(7-9)$ or other areas $(2,3,9)$. However, all healthcare workers from Guinea who we treated were infected in their communities or when providing care in other healthcare facilities $(7,8)$. In the Healthcare Workers Treatment Center, we observed a high incidence of 3.5 occupational exposures/healthcare worker/year, which was much higher than the incidence of 0.077 occupational exposures/nurse/year typically observed in hospitals in France (10). This high incidence was responsible of excessive concern by some of the healthcare workers from France. However, this concern should be balanced by the low risk for Ebola virus transmission for each exposure.

Classification of transmission risk was difficult. The French recommendations (5) were established for exposures in hospitals in France and were not adapted for poorly equipped hospitals (e.g., the Healthcare Workers Treatment Center was composed of tents and direct contact with infected walls was frequent because of lack of space and displacement of googles or masks). Data show that infection with Ebola virus from environment is possible (11). More than $80 \%$ of occupational exposures were at low risk for virus transmission and did not justify prescription of antiviral treatment, such as favipiravir, which has been used to prevent EVD infection despite lack of data concerning its efficiency (12-14). A large part of skin exposure should be avoided by improving PPE and limiting activities could displace goggles or masks.

We observed various circumstances that could affect exposure to Ebola virus. In contrast to what we expected (4), exposure incidents during removal of PPE were rare, probably because healthcare workers are extensively trained for this activity. Thus, an increase in infections was not observed. No demographic, professional, or incidental factors were associated with a higher frequency of risk exposure. Obtaining a blood sample was a high-risk activity because this can be a stressful procedure and because of constraints associated with PPE, such as an increased core body temperature (15).

Technical training for healthcare workers dealing with EVD patients should be increased. A large number of occupational exposures occurred in the first month of the study, which showed that more technical experience could decrease the risk for infection. Despite the high incidence of occupational exposures, no infections occurred during or after the study, which showed that countermeasures we implemented were efficient in preventing virus transmission. Nosocomial transmission of Ebola virus can be avoided by appropriate materials, reliable biosafety protocols, and training. These suggestions could explain why only a few cases of transmission at the Ebola Treatment Center were observed. However, improvements in PPE components, training of healthcare workers, and PEP strategy are required to face future outbreaks of virus diseases.

\section{Acknowledgments}

We thank all healthcare workers at the Healthcare Workers Treatment Center and the Health Supplies Center of the French Military Health Service for support, participation, and assistance.

Dr. Savini is medical practitioner in the unit of infectious and tropical disease, Military Teaching Hospital of Laveran, Marseille, France. Her primary research interest is travel medicine, notably imported malaria.

\section{References}

1. World Health Organization. Health workers Ebola infections in Guinea, Liberia, and Sierra Leone. A preliminary report [cited 2015 May 21]. http://apps.who.int/iris/bitstream/10665/171823/1/ WHO_EVD_SDS_REPORT_2015.1_eng.pdf

2. Lopaz MA, Amela C, Ordobas M, Dominguez-Berjon MF, Alvarez C, Martinez M, et al. Working group of Ebola outbreak investigation team of Ma=drid. Euro Surveill. 2015;20:pii:21003.

3. Liddell AM, Davey RT Jr, Mehta AK, Varkey JB, Kraft CS, Tseggay GK, et al. Characteristics and clinical management of a cluster of 3 patients with Ebola virus disease, including the first domestically acquired cases in the United States. Ann Intern Med. 2015;163:81-90. http://dx.doi.org/10.7326/M15-0530

4. Zellmer C, Van Hoof S, Safdar N. Variation in health care worker removal of personal protective equipment. Am J Infect Control. 2015;43:750-1. http://dx.doi.org/10.1016/j.ajic.2015.02.005

5. French High Council on Public Health. Advice relative to the management of an occupational exposure from a patient with suspected of proven Ebola viral disease [in French] [cited 2014 Dec 4]. http://www.hscp.fr

6. Mulligan MJ, Siebert PN. Era of global Ebola: risk of exposure in health-care workers. Lancet Infect Dis. 2015;15:1248-9. http://dx.doi.org/10.1016/S1473-3099(15)00291-1

7. Grinnell M, Dixon MG, Patton M, Fitter D, Bilivogui P, Johnson C, et al. Ebola virus disease in health care workersGuinea, 2014. MMWR Morb Mortal Wkly Rep. 2015;64:1083-7. http://dx.doi.org/10.15585/mmwr.mm6438a6

8. Olu O, Kargbo B, Kamara S, Wurie AH, Amone J, Ganda L, et al. Epidemiology of Ebola virus disease transmission among health care workers in Sierra Leone, May to December 2014: a retrospective descriptive study. BMC Infect Dis. 2015;15:416. http://dx.doi.org/10.1186/s12879-015-1166-7

9. Forrester JD, Hunter JC, Pillai SK, Arwady MA, Ayscue P, Matanock A, et al. Cluster of Ebola cases among Liberian and U.S. health care workers in an Ebola treatment unit and adjacent hospital-Liberia, 2014. MMWR Morb Mortal Wkly Rep. 2014;63:925-9.

10. Tarantola A, Golliot F, Astagneau P, Fleury L, Brücker G, Bouvet E; CCLIN Paris-Nord Blood and Body Fluids (BBF) Exposure Surveillance Taskforce. Occupational blood and body fluids 
exposures in health care workers: four-year surveillance from the northern France network. Am J Infect Control. 2003;31:357-63. http://dx.doi.org/10.1016/S0196-6553(03)00040-3

11. Youkee D, Brown CS, Lilburn P, Shetty N, Brooks T, Simpson A, et al. Assessment of environmental contamination and environmental decontamination practices within an Ebola holding unit, Freetown, Sierra Leone. PLoS One. 2015;10:e0145167. http://dx.doi.org/10.1371/journal.pone.0145167

12. Smither SJ, Eastaugh LS, Steward JA, Nelson M, Lenk RP, Lever MS. Post-exposure efficacy of oral T-705 (favipiravir) against inhalational Ebola virus infection in a mouse model. Antiviral Res. 2014;104:153-5. http://dx.doi.org/10.1016/j.antiviral.2014.01.012

13. Van Herp M, Declerck H, Decroo T. Favipiravir - a prophylactic treatment for Ebola contacts? Lancet. 2015;385:2350. http://dx.doi.org/10.1016/S0140-6736(15)61095-9
14. Jacobs M, Aarons E, Bhagani S, Buchanan R, Cropley I, Hopkins S, et al. Post-exposure prophylaxis against Ebola virus disease with experimental antiviral agents: a case-series of health-care workers. Lancet Infect Dis. 2015;15:1300-4. http://dx.doi.org/10.1016/S1473-3099(15)00228-5

15. Grélot L, Koulibaly F, Maugey N, Janvier F, Foissaud V, Aletti M, et al. Moderate thermal strain in healthcare workers wearing personal protective equipment during treatment and care activities in the context of the 2014 Ebola virus disease outbreak. J Infect Dis. 2015.

Address for correspondence: Helene Savini, Department of Infectious and Tropical Disease, French Military Teaching Hospital Laveran, 34 Bd Laveran, 13013 Marseille, France; email: helene.savini13@gmail.com

\section{July 2009: Vectorborne Diseases}

- Sylvatic Epidemic Typhus Associated with Flying Squirrels

- Host Species Diversity and Prevalence of Sin Nombre Virus

- Lymphocytic Choriomeningitis Virus in Wild Rodents, Northern Italy

- Tick-borne Relapsing Fever and Borrelia hermsii, Los Angeles County, California, USA

- Risk Factors for Human Infection with Puumala Virus, Southwestern Germany

- Invasions by Eurasian Avian Influenza Virus H6 Genes and Replacement of the Virus' North American Clade

- Multiple Origins of Foot-and-Mouth Disease Virus Serotype Asia 1 Outbreaks

- Clusters of Multidrug-Resistant Mycobacterium tuberculosis Cases, Europe

- Relapse Associated with Active Disease Caused by Beijing Strain of Mycobacterium tuberculosis

- Azole Resistance in Aspergillus fumigatus Associated with Treatment Failure

- Co-infections with Chikungunya Virus and Dengue Virus in Delhi, India

- Influenza Virus A (H1N1) in Giant Anteaters

- Lack of Macrolide Resistance in Chlamydia trachomatis after Azithromycin Distributions
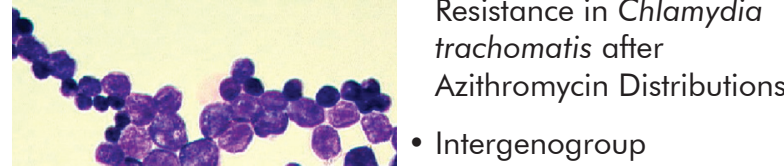
Recombinant Sapovirus in Japan, 2007-2008

- Arcanobacterium pyogenes Sepsis in Farmer, Brazil

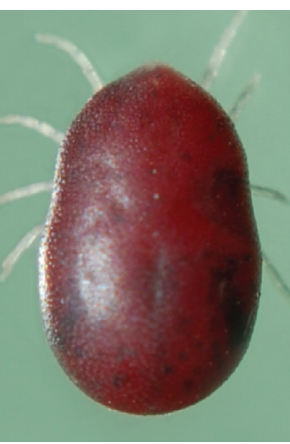

- Coronaviruses in Wild Bird Populations of Northern England

- WU Polyomavirus in Patients Infected with HIV or Hepatitis C Virus, Connecticut, USA

- Methicillin-Resistant Staphylococcus aureus ST398 in Swine Farm Personnel, Belgium

- Eczema Herpeticum and Clinical Criteria for Investigating Smallpox

- Rickettsia slovaca and R. raoultii in Tick-borne Rickettsioses

- Scrub Typhus, South Korea, 2001-2006

- Latent Tuberculosis and Active Disease Rates among the Homeless, New York, New York, USA

- Chinese-like Strain of Porcine Epidemic Diarrhea Virus, Thailand

- Human T-cell Lymphotropic Virus Type 1 Infection in Blood Donors, Israel

- Recurrent Lymphocytic Meningitis and Herpes Simplex Virus Type 2

- Possible Streptomycin-Resistant Mycobacterium tuberculosis Beijing, Benin

- Rickettsia felis Infection in Man, France

- Fatal Algaemia and Chronic Lymphocytic Leukemia

- Reactivation of Bovine Tuberculosis in Patient Treated with Infliximab

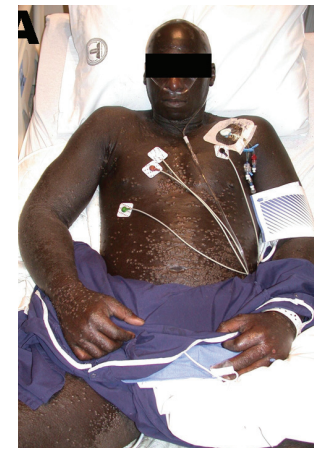

